\title{
Activity and abundance of methane-oxidizing bacteria in secondary forest and manioc plantations of Amazonian Dark Earth and their adjacent soils
}

\author{
Amanda B. Lima ${ }^{1}$, Aleksander W. Muniz ${ }^{2}$ and Marc G. Dumont ${ }^{1}{ }^{*}$ \\ ${ }^{1}$ Department of Biogeochemistry, Max Planck Institute for Terrestrial Microbiology, Marburg, Germany \\ ${ }^{2}$ Department of Soil Microbiology and Biogeochemistry, Brazilian Agricultural Research Corporation, Manaus, Brazil
}

\section{Edited by:}

Steffen Kolb, University of Bayreuth, Germany

\section{Reviewed by:}

Sascha M. B. Krause, University of Washington, USA

Peter Dunfield, University of Calgary, Canada

\section{${ }^{*}$ Correspondence:}

Marc G. Dumont, Department of Biogeochemistry, Max Planck Institute for Terrestrial Microbiology, Karl-von-Frisch-Straße 10, D-35043 Marburg, Germany

e-mail: dumont@mpi-marburg.mpg.de
The oxidation of atmospheric $\mathrm{CH}_{4}$ in upland soils is mostly mediated by uncultivated groups of microorganisms that have been identified solely by molecular markers, such as the sequence of the $p m o A$ gene encoding the $\beta$-subunit of the particulate methane monooxygenase enzyme. The objective of this work was to compare the activity and diversity of methanotrophs in Amazonian Dark Earth soil (ADE, Hortic Anthrosol) and their adjacent non-anthropic soil. Secondly, the effect of land use in the form of manioc cultivation was examined by comparing secondary forest and plantation soils. $\mathrm{CH}_{4}$ oxidation potentials were measured and the structure of the methanotroph communities assessed by quantitative PCR (qPCR) and amplicon pyrosequencing of pmoA genes. The oxidation potentials at low $\mathrm{CH}_{4}$ concentrations (10 ppm of volume) were relatively high in all the secondary forest sites of both ADE and adjacent soils. $\mathrm{CH}_{4}$ oxidation by the ADE soil only recently converted to a manioc plantation was also relatively high. In contrast, both the adjacent soils used for manioc cultivation and the ADE soil with a long history of agriculture displayed lower $\mathrm{CH}_{4}$ uptake rates. Amplicon pyrosequencing of pmoA genes indicated that USC $\alpha$, Methylocystis and the tropical upland soil cluster (TUSC) were the dominant groups depending on the site. By qPCR analysis it was found that USC $\alpha$ pmoA genes, which are believed to belong to atmospheric $\mathrm{CH}_{4}$ oxidizers, were more abundant in ADE than adjacent soil. USC $\alpha$ pmoA genes were abundant in both forested and cultivated ADE soil, but were below the qPCR detection limit in manioc plantations of adjacent soil. The results indicate that $\mathrm{ADE}$ soils can harbor high abundances of atmospheric $\mathrm{CH}_{4}$ oxidizers and are potential $\mathrm{CH}_{4}$ sinks, but as in other upland soils this activity can be inhibited by the conversion of forest to agricultural plantations.

Keywords: methane oxidation, Amazonian Dark Earth, terra preta de índio, methanotroph, pmoA, USC- $\alpha$, Methylocystis

\section{INTRODUCTION}

Most soils in the Amazon region have low fertility. Typically, Amazonian soils are acidic, have low $\mathrm{P}$ contents, low cation exchange capacity and high levels of $\mathrm{Al}$ at levels that can be toxic to crops (Cochrane and Sanchez, 1982). In contrast, Amazonian Dark Earth (ADE) soils, also known as terra preta de índio, are fertile soil patches found dispersed throughout the Amazon that were formed by the ancient Amazonian indigenous populations. It is believed that these soils were unintentionally or intentionally formed by long-term habitation with casual addition of domestic refuse and by long-lasting agricultural activity based on the clearing of vegetation and the incomplete combustion of organic material (Smith, 1980; Denevan, 1998; Glaser, 1999). Unlike their adjacent soils, $\mathrm{ADE}$ have high contents of $\mathrm{P}, \mathrm{Ca}, \mathrm{Mg}, \mathrm{Zn}, \mathrm{Mn}$, and stable organic matter (Costa and Kern, 1999; Woods and McCann, 1999).

Differences in bacterial community structure and composition have been observed under different land use systems in Amazonian soils (Jesus et al., 2009; Navarrete et al., 2010; Taketani et al., 2013), which will in turn influence ecosystem processes such as the decomposition of organic matter and nutrient mineralization or its immobilization (Neher, 1999). In addition, the bacterial communities in ADE soils were shown by $16 \mathrm{~S}$ rRNA tag sequence analysis to be distinct from their adjacent soils, particularly when compared at taxonomic levels lower than phylum (Taketani et al., 2013). One of the possible influences on the microbial communities of ADE soils is the presence of large amounts of biochar, which have prompted research into the effect of biochar application on microbial community structure and composition (Anderson et al., 2011; Khodadad et al., 2011). Replicating the high carbon and biochar contents of ADE in other soils has been suggested as a mechanism of $\mathrm{CO}_{2}$ sequestration (Sombroek et al., 2003; Lehmann, 2007); however, the presence of these relatively large amounts of carbon in $\mathrm{ADE}$ then raises concern whether changes in climate and land use may result in increased emissions of $\mathrm{CO}_{2}$ and $\mathrm{CH}_{4}$. One possible mechanism of increased $\mathrm{CH}_{4}$ emissions would be the decomposition of labile components of biochar to form substrates for methanogens (Knoblauch et al., 
2008). To our knowledge, $\mathrm{CH}_{4}$ cycling in ADE soil has not been investigated and one important question is whether methaneoxidizing bacteria (methanotrophs) are present and active in ADE soils. If present, methanotrophs could consume atmospheric $\mathrm{CH}_{4}$ or potentially mitigate the release to the atmosphere of $\mathrm{CH}_{4}$ produced endogenously in the soil.

Upland soils, defined as those that are typically well-drained and oxic, have an important role in the global $\mathrm{CH}_{4}$ cycle by acting as a sink for atmospheric $\mathrm{CH}_{4}$ (King, 1992), which globally is estimated at more than $30 \mathrm{Tg} \mathrm{y}^{-1}$ (Denman et al., 2007). Although this activity is found in a wide variety of upland soils, pristine forest soils have been identified as the most efficient biological sinks of atmospheric $\mathrm{CH}_{4}$ (Dunfield, 2007; Dalal and Allen, 2008). Numerous studies have shown that the conversion of pristine land to agriculture lowers the oxidation capacity of the soil (Keller et al., 1990; Mosier et al., 1991; Hütsch et al., 1994; Jensen and Olsen, 1998; Priemé and Christensen, 1999; Knief et al., 2005; Levine et al., 2011). Various factors associated with agriculture have been shown to inhibit atmospheric $\mathrm{CH}_{4}$ oxidation, including soil compaction, acidification and fertilization (Dunfield, 2007). Conversely, the abandonment of agriculture can also lead to at least partial recovery of methanotroph populations and atmospheric $\mathrm{CH}_{4}$ uptake (Levine et al., 2011). ADE soils are commonly found on well-drained areas of the Amazon region (terra firme), and may also be sinks for atmospheric $\mathrm{CH}_{4}$.

Methanotroph diversity and activity has been assessed in different upland soils exhibiting atmospheric $\mathrm{CH}_{4}$ oxidation (Dunfield, 2007; Kolb, 2009). The diversity of atmospheric $\mathrm{CH}_{4}$ oxidizers is typically assessed by the detection of the $p m o A$ gene, which encodes the $\beta$-subunit of methane monooxygenase (pMMO) enzyme (McDonald etal., 2008; Semrau etal., 2010). For the most part, as yet uncultivated microorganisms mediate atmospheric $\mathrm{CH}_{4}$ oxidation and are characterized by their pmoA gene sequences alone. In addition, phospholipid fatty acids have been used to identify atmospheric $\mathrm{CH}_{4}$ oxidizers (Bodelier et al., 2009). The USC $\alpha$ pmoA clade is widely distributed in upland soils (Knief etal., 2003) and based on gene analyses are believed to belong to Alphaproteobacteria most closely related to Methylocapsa (Ricke etal., 2005). The USC $\gamma$ pmoA clade is another associated with upland soils exhibiting atmospheric $\mathrm{CH}_{4}$ uptake, and appear to favor neutral or somewhat alkaline soils (Knief et al., 2003). Another clade termed JR3, initially identified in grassland soil (Horz et al., 2005) was found to dominate in desert soils with atmospheric $\mathrm{CH}_{4}$ oxidation capacity (Angel and Conrad, 2009). Methylocystis-related species have been shown to use $\mathrm{CH}_{4}$ at relatively low concentrations (Knief and Dunfield, 2005; Knief et al., 2006; Baani and Liesack, 2008), but whether they are important consumers of atmospheric $\mathrm{CH}_{4}$ in upland soils is not clear.

To our knowledge, no studies have previously examined $\mathrm{CH}_{4}$ oxidation or the diversity of methanotrophs in ADE soils. The primary objective of this study was to determine the extent to which $\mathrm{ADE}$ soils are a potential sink for atmospheric $\mathrm{CH}_{4}$ and secondly to determine how the methanotroph community structure and their $\mathrm{CH}_{4}$ uptake potential compares between forested and agricultural sites.

\section{MATERIALS AND METHODS STUDY AREA, SOIL SAMPLING, AND SOIL ANALYSIS}

Soil samples were collected from two different areas, Caldeirão and Barro Branco. The Caldeirão experimental research station from Embrapa Amazônia Ocidental is located in Iranduba County in the Brazilian Central Amazon (03 $\left.26^{\prime} 00^{\prime \prime} \mathrm{S}, 60^{\circ} 23^{\prime} 00^{\prime \prime} \mathrm{W}\right)$. The other sampling area near the Barro Branco community is located in the Manacapuru County in the Brazilian Central Amazon $\left(03^{\circ} 18^{\prime} 12^{\prime \prime} \mathrm{S}, 60^{\circ} 31^{\prime} 45^{\prime \prime} \mathrm{W}\right)$. ADE soils and their adjacent soils were collected from both areas. In both cases, the distance between the ADE soil zone and the adjacent soil zone was $\sim 2 \mathrm{~km}$.

The soils were classified based on the World Reference Base for Soil Resources (FAO, 1998). ADE soils were classified as Hortic Anthrosol (i.e., reference horizon that results from prolonged habitation with casual additions of domestic organic refuse and cultural material). The adjacent soil from Caldeirão was classified as Haplic Acrisol (i.e., clay-rich soils with low fertility and toxic amounts of $\mathrm{Al}$ ). The adjacent soil from Barro Branco was classified as Oxisol (i.e., red or yellowish soils with $<10 \%$ weatherable minerals and low cation exchange capacity). At both areas, ADE soil and adjacent soil were sampled from secondary forest sites and agricultural sites cultivated with manioc (Manihot esculenta). The forested $\mathrm{ADE}$ and adjacent soil sites at Caldeirão were under $\sim 40$-year-old secondary forest stands. At Barro Branco, the secondary forests were about 20 years-old. The agricultural sites in ADE and adjacent soils at Caldeirão had been used for manioc cultivation for at least 40 years, whereas the sites at Barro Branco had been deforested 5-years previously for conversion to plantations.

Soil samples were collected in February 2013. Three environmental replicates were collected from each sampling site. The sample plot (location) at each site was determined by choosing a random point, and from this reference point three sampling points (sublocations) $5 \mathrm{~m}$ apart were chosen for the collection of intact soil cores of $5 \mathrm{~cm}$ in diameter and $15 \mathrm{~cm}$ in length. Soil samples were collected in triplicate from each sublocation, which were subsequently homogenized to produce a composite soil sample for each sublocation. A total of 24 samples corresponding to the four sites (forested ADE, cultivated ADE, forested adjacent, and cultivated adjacent) from each of the two areas (Caldeirão and Barro Branco) were prepared. The samples for DNA extraction were transported from the field to the laboratory in an insulated box with dry ice. Approximately $1 \mathrm{~kg}$ of soil samples were collected from each of the 24 sublocations and sent to the department of Soil and Plant Nutrition of Embrapa Western Amazon. The frozen and unsieved soil samples were used for DNA extraction, whereas the $1 \mathrm{~kg}$ samples of fresh soil were sieved ( $2 \mathrm{~mm}$ mesh diameter) and used for the determination of soil chemical properties and $\mathrm{CH}_{4}$ oxidation potentials. Soil $\mathrm{pH}\left(\mathrm{H}_{2} \mathrm{O}, 1: 1\right)$, soil extractable $\mathrm{Al}$, $\mathrm{Ca}, \mathrm{Fe}, \mathrm{K}, \mathrm{Mg}, \mathrm{Mn}, \mathrm{P}, \mathrm{Zn}$, soil organic carbon (SOC), total C, total $\mathrm{N}$, and cation exchange capacity were determined according to the methods described by Embrapa (1997).

\section{$\mathrm{CH}_{4}$ OXIDATION}

Potential $\mathrm{CH}_{4}$ oxidation rates were measured using soil from each sampling point (sublocation). Ten grams of fresh sieved soil was 
placed into a $120 \mathrm{ml}$ serum vial in duplicate (Bull et al., 2000; Horz et al., 2002; Shrestha etal., 2012). The bottles were sealed with butyl rubber stoppers, and final mixing ratios of 10, 100, 1000, and $10000 \mathrm{ppmv}$ of $\mathrm{CH}_{4}$ was injected into the gas headspace of the vials. The incubation of soil microcosms was performed at $25^{\circ} \mathrm{C}$ in the dark with shaking at $150 \mathrm{rpm}$ for up to 19 days. $\mathrm{CH}_{4}$ concentrations were measured on a daily basis by gas chromatography with a flame ionization detector using $0.5 \mathrm{ml}$ gas samples from the bottle headspaces, as described previously (Shrestha et al., 2012). $\mathrm{CH}_{4}$ oxidation rates were calculated by linear regression of $\mathrm{CH}_{4}$ consumption versus time for the incubations with $10 \mathrm{ppm} \mathrm{CH}_{4}$.

\section{DNA EXTRACTION FROM SOIL SAMPLES}

Soil DNA extractions were carried out in triplicate from $0.3 \mathrm{~g}$ wet weight subsamples of each soil sample. Extractions were performed using the Nucleospin soil DNA extraction kit (MachereyNagel, Düren, Germany) according to the manufacturer's instructions. DNA was quantified using a Qubit dsDNA HS Assay (Molecular Probes, Invitrogen, USA). The triplicate DNA extracts of each sampling sublocation were pooled.

\section{REAL-TIME QUANTITATIVE PCR ASSAYS}

Real-time quantitative PCR (qPCR) with three technical replicates for each sublocation DNA sample was performed to determine the copy numbers of the pmoA genes. The qPCR assay using the primer set A189f-mb661r was used to target the conventional pmoA genes of Methylocystaceae and Methylococcaceae methanotrophs (Costello and Lidstrom, 1999; Kolb et al., 2003). The assay using primers A189f-Forest675r was used to target USC $\alpha$ pmoA genes (Kolb et al., 2003). The qPCRs were performed with the SYBR Green JumpStart Taq ReadyMix System (Sigma, Taufkirchen, Germany) on an iCycler instrument (Bio-Rad, Munich, Germany). The data were analyzed using Bio-Rad CFX Manager (version 3.0) software. PCR mixtures and thermal cycling conditions were performed as described previously by Kolb et al. (2003). Briefly, the A189f-Forest675r assay was performed in $25 \mu \mathrm{l}$ reaction mixtures containing $12.5 \mu \mathrm{l}$ of SYBR Green Jump-Start Taq Ready Mix (Sigma), $1 \mu \mathrm{M}$ of each primer, $50 \mathrm{ng}$ of BSA (Roche, Mannheim, Germany), and $4 \mathrm{mM} \mathrm{MgCl}_{2}$ (Sigma). The assay for the abundance of conventional pmoA genes (A189f-mb661r) was performed in $25-\mu 1$ reaction mixtures containing $12.5 \mu 1$ of SYBR Green JumpStart Taq Ready Mix (Sigma), $0.667 \mu \mathrm{M}$ of each primer and $4 \mathrm{mM}$ $\mathrm{MgCl}_{2}$. Standards for $\mathrm{qPCR}$ were generated by serial dilution of stocks of a known number of plasmids containing a single cloned copy of a Methylococcus pmoA gene or a USC $\alpha$ pmoA gene, according to the assay. All samples from an experiment were run on a single plate.

\section{HIGH-THROUGHPUT SEQUENCING AND ANALYSIS}

PCR was performed using the primers A189f and A682r that amplify a broad range of $p m o A$, amoA, and related sequences (Holmes et al., 1995; Lüke and Frenzel, 2011). The PCR components and conditions were identical to that described previously (Angel and Conrad, 2009). Briefly, the $50 \mu \mathrm{l}$ reaction contained $5 \mu \mathrm{l}$ of 10x AccuPrime ${ }^{\mathrm{TM}}$ PCR Buffer II (Invitrogen, Karlsruhe, Germany), additional $1.5 \mathrm{mM} \mathrm{MgCl}_{2}$ (to a final concentration of
$3 \mathrm{mM}$ ), $0.5 \mathrm{mM}$ of each primer (Sigma), $50 \mathrm{ng}$ of BSA (Roche) and $1 \mu l$ of Taq DNA polymerase (Invitrogen). All ADE samples could be amplified directly with the barcoded primer sets; however, it was not possible to obtain amplicons of the expected size for the adjacent soil samples using these primers. Therefore, a 2-step PCR procedure in which conventional primers (i.e., without barcodes) was used in the first step followed by a successive low-cycle-number amplification using the barcoded primers, as described by Berry et al. (2011). This approach successfully produced PCR amplicons of the expected size. To allow comparisons, the same 2-step PCR approach was used for all samples. Five replicate PCR reactions were performed for each sample. After amplification, PCR reactions were pooled and loaded on $1 \%$ agarose gel stained in GelRed $^{\mathrm{TM}}$ (Biotium Inc., Hayward, CA, USA). The DNA fragment of the correct size was excised from the agarose gel and eluted in $30 \mu l \mathrm{H}_{2} \mathrm{O}$ using the QIAquick gel extraction kit (Qiagen, Hilden, Germany). The purified PCR products from all samples were mixed in a 1:1 ratio and sequenced at the Max Planck-GenomeCentre Cologne (Cologne, Germany) using a Roche 454 Genome Sequencer FLX System.

A detailed description of the procedures used for sequence analysis was described previously (Dumont et al., 2014). In this study, only sequences with read lengths longer than $300 \mathrm{bp}$ were used for further analysis. The sorting of sequences according to barcodes, trimming and quality filtering were processed using mothur version 1.29.2 (Schloss et al., 2009). Chimeric sequences were identified and removed using uchime (Edgar et al., 2011) implemented in mothur. Classification of $p m o A$ sequences was performed using standalone TBLASTN version 2.2.26+ against a curated database of pmoA sequences and the lowest common ancestor (LCA) algorithm in MEGAN version 4.70.4 (Huson et al., 2011), as described previously (Dumont et al., 2014). A total of 110,437 sequences were obtained. 42,213 reads (a range from 9022 to 2977 reads per library) remained after basic quality filtering. The amplification of non-target sequences is common with these primers (Bourne et al., 2001) and these contaminants were identified by an absence of similarity to the reference database and removed from further analysis. The contaminants corresponded to an average of 57\% from ADE samples and $87 \%$ from adjacent soil samples. A total of 13,595 reads remained after removing these contaminant sequences, corresponding to an average of 2802 reads from ADE and 597 from adjacent soil samples.

Representative sequences from each $p m o A$ clade identified during the sequence analysis were selected for further analysis. These reads were translated into amino acid sequences and added to a reference pmoA/amoA phylogenetic tree using parsimony in ARB (Ludwig et al., 2004).

Sequences are available through the Metagenomics Rapid Annotation (MG-RAST) server ${ }^{1}$ with accession numbers 4577576.3 (TPISFBB2), 4577577.3 (TPISFBB3), 4577578.3 (TPISFBB4), 4577570.3 (TPIMBB2), 4577571.3 (TPIMBB3), 4577572.3 (TPIMBB5), 4577565.3 (ADJSFBB2), 4577566.3 (ADJSFBB3), 4577560.3 (ADJMBB2), 4577561.3 (ADJMBB3), 4577562.3 (ADJMBB4), 4577579.3 (TPISFC3), 4577580.3

${ }^{1}$ http://metagenomics.anl.gov/ 
(TPISFC4), 4577581.3 (TPISFC5), 4577573.3 (TPIMC2), 4577574.3 (TPIMC3), 4577575.3 (TPIMC4), 4577567.3 (ADJSFC2), 4577568.3 (ADJSFC4), 4577569.3 (ADJSFC5), 4577563.3 (ADJMC3), 4577564.3 (ADJMC4).

\section{STATISTICS}

Differences in soil chemical properties were tested by one-way analysis of variance. Two-way analysis of variance model was used to assess differences in $p m o A$ gene abundances between land uses and soil types. Test of proportions was used to observe significance of proportion difference in $p m o A$ gene relative abundance generated by amplicon pyrosequencing between $\mathrm{ADE}$ and adjacent soils using prop.test in the $\mathrm{R}$ Stats Package ${ }^{2}$. Significance level of $p<0.05$ was applied for all statistical analyses and performed using R version 3.03 (R Foundation for Statistical Computing).

\section{RESULTS}

\section{SOIL CHEMICAL PROPERTIES}

The soil chemical properties are presented in Table 1. As previously reported, the measured soil chemical properties at the Caldeirão Experimental Station showed a clear distinction between ADE and adjacent soil samples (Taketani et al., 2013; Brossi et al., 2014). ADE soils from Barro Branco had similar properties to those at Caldeirão, with relatively high $\mathrm{pH}, \mathrm{Ca}, \mathrm{CEC}, \mathrm{K}, \mathrm{Mg}, \mathrm{Mn}, \mathrm{P}, \mathrm{SOC}$, and $\mathrm{Zn}$ compared to their adjacent soils. These characteristics indicate the potential for high agricultural productivity. In contrast, the adjacent soils (i.e., Haplic Acrisol and Oxisol) had lower pH and higher $\mathrm{Al}$ and $\mathrm{Fe}$.

\section{SOIL $\mathrm{CH}_{4}$ OXIDATION POTENTIALS}

$\mathrm{CH}_{4}$ oxidation was immediate at concentrations of 10 and 100 ppmv, but a lag phase of 6-10 days was observed for concentrations of 1000 and 10,000 ppmv (results not shown). Relatively high rates of high-affinity $\mathrm{CH}_{4}$ oxidation ( $10 \mathrm{ppm} \mathrm{CH}_{4}$ ) were observed in all soils from the forested sites and the ADE soil used for manioc cultivation at the Barro Branco area (Table 2). In contrast, the $\mathrm{CH}_{4}$ oxidation rates were more than one-order of magnitude lower in both plantations in adjacent soil and the ADE plantation soil at Caldeirão. The precise history of these soils is not available, but members of the local communities indicated that manioc has been cultivated in ADE soil at the Caldeirão site for living memory ( $>40$ years), whereas the Barro Branco ADE soil was only recently (5 years) converted from forest to agriculture by slash-and-burn.

\section{ABUNDANCE OF METHANOTROPHS}

Quantitative real-time PCR assays were used to determine the copy numbers of $p m o A$ genes in ADE and adjacent soils from both secondary forest and the manioc cultivation sites (Figure 1). The pmoA qPCR assay with primers A189f-mb661r targets methanotrophs belonging to the Methylococcaceae and Methylocystaceae families and generally has poor specificity for the genes from other families of methanotrophs. The abundance of genes detected with this assay (Figure 1A) was not significantly affected by soil type or land use. Based on the diversity of $p m o A$ genes detected in the soils (Figure 2), these results correspond to Methylocystis pmoA

\footnotetext{
${ }^{2} \mathrm{http}: / /$ www.r-project.org
}

genes. Another qPCR assay was used to specifically enumerate USC $\alpha$ pmoA, which are a common uncultivated group associated with atmospheric $\mathrm{CH}_{4}$ oxidation. In ADE soils, the abundances of USC $\alpha$ pmoA (Figure 1B) were more than two-orders of magnitude higher than Methylocystis pmoA genes (Figure 1A). USC $\alpha$ were below the detection limit $\left(1 \times 10^{4}\right.$ copies $g^{-1}$ dry weight soil) in the plantations of adjacent soils. Taking the data from Barro Branco and Caldeirão sites together, the abundance of USC $\alpha$ pmoA was significantly higher in ADE than adjacent soil (ANOVA, $p<0.0001$ ), but the difference in abundance based on land use (forested versus cultivated) was not significant (ANOVA, $p=0.77)$.

\section{COMPOSITION OF METHANOTROPH COMMUNITIES}

The methanotroph communities in the soils were analyzed by pmoA gene pyrosequencing. PCR using the A189f-A682r primer combination retrieves diverse $p m o A$-related genes, including the proteobacterial $p m o A$ genes and those from uncultivated methanotrophs believed to be responsible for atmospheric $\mathrm{CH}_{4}$ uptake in upland soils (McDonald et al., 2008). A known problem with these primers is a tendency to co-amplify non-specific sequences, which can make clone libraries useless (Bourne et al., 2001). Non-specific amplification with these primers was also observed in our pyrosequencing data, with an average of $87 \%$ of reads from adjacent soils corresponding to non-target reads. The advantage of relatively high number of reads obtainable by pyrosequencing compared with clone libraries meant that sufficient numbers of genuine pmoA sequences were still available to allow for comparisons in pmoA diversity between the samples.

Almost all sequences passing the quality-filtering steps were assigned to seven clades, which were defined and described previously (Lüke and Frenzel, 2011). Representative sequences from each of these clades were added to a database of $p m o A$ and $a m o A$ sequences and are shown in a simplified phylogenetic tree (Figure 2). The most abundant clades identified were USC $\alpha$, tropical upland soil cluster (TUSC) and Methylocystis. The other less abundant clades were RA21, M84-P105, AOB-rel, and the AOBlike group. AOB-rel is also referred to in the literature as Cluster 1 (Kolb et al., 2005).

The relative abundance of the clades from each of the sites is shown in Figure 3. A test of proportions indicated that, with the exception of AOB-like sequences, the relative abundances of these clades were significantly different $(p<0.05)$ between the ADE and the adjacent soils (Table S1).

\section{COMPARISON OF RELATIVE PTOA GENE ABUNDANCES OBTAINED BY qPCR AND PYROSEQUENCING}

Data from the $p m o A$ qPCR assays and amplicon pyrosequencing approaches provided independent numbers to compare the relative abundance of $p m o A$ clades in the soils. Based on the diversity of pmoA detected by pyrosequencing, Methylocystis was the only group present that was a target for the A189f-mb661r pmoA qPCR assay. Therefore, the abundance of $p m o A$ detected with this qPCR assay was taken as the abundance of Methylocystis pmoA genes. Calculating the relative abundance of Methylocystis and USC $\alpha$ from the qPCR assays (Figure 4A) and the pyrosequencing dataset (Figure 4B) showed relatively good agreement. 


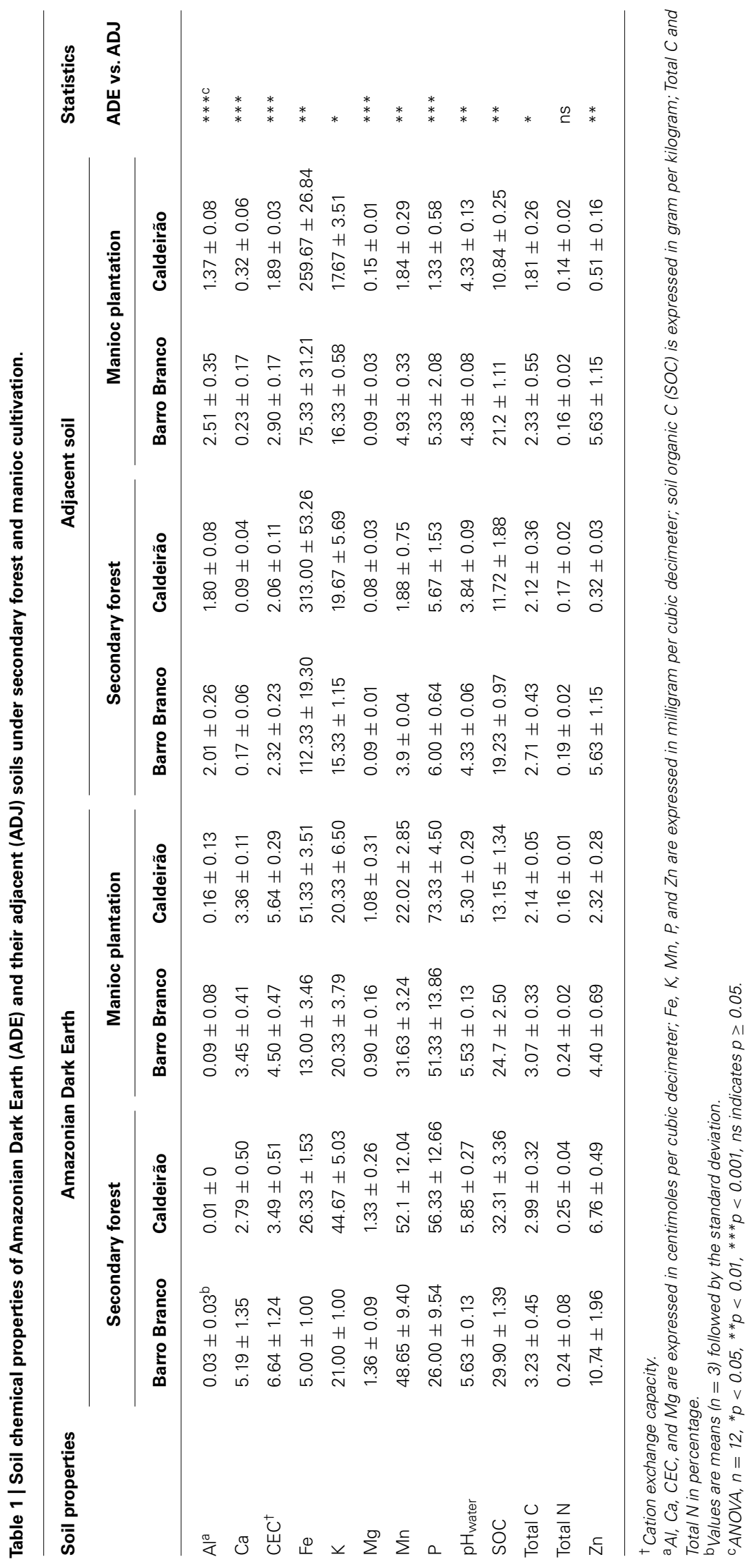


Table $2 \mid \mathrm{CH}_{4}$ oxidation rates in Amazonian Dark Earth and their adjacent soils under secondary forest and manioc cultivation.

\begin{tabular}{|c|c|c|}
\hline Soil type and site & Land use & $\begin{array}{l}\mathrm{CH}_{4} \text { oxidation rate } \\
\left.\text { [pmol of } \mathrm{CH}_{4}(g \mathrm{dw})^{-1} \mathrm{~h}^{-1}\right]\end{array}$ \\
\hline \multicolumn{3}{|c|}{ Amazonian Dark Earth } \\
\hline Barro Branco & Secondary forest & $33.5 \pm 1.6$ \\
\hline Caldeirão & Secondary forest & $48.1 \pm 4.5$ \\
\hline Barro Branco & Manioc plantation & $50.0 \pm 1.4$ \\
\hline Caldeirão & Manioc plantation & $6.0 \pm 1.1$ \\
\hline \multicolumn{3}{|l|}{ Adjacent soil } \\
\hline Barro Branco & Secondary forest & $31.0 \pm 1.9$ \\
\hline Caldeirão & Secondary forest & $21.0 \pm 1.7$ \\
\hline Barro Branco & Manioc plantation & $8.0 \pm 1.9$ \\
\hline Caldeirão & Manioc plantation & $6.1 \pm 2.2$ \\
\hline
\end{tabular}

a Errors are standard deviation $(n=3)$.

The major difference between these data was that USC $\alpha$ in the cultivated adjacent soils was below the detection limit of the qPCR assay (Figure 1B) and therefore its relative abundance was calculated as 0 (Figure 4A); however, USC $\alpha$ sequences were detected of $\sim 20 \%$ of Methylocystis in the pyrosequencing dataset from these samples (Figure 4B).

\section{DISCUSSION}

Many processes, such as $\mathrm{CH}_{4}$ oxidation, are crucial for soil ecosystem functioning and have an impact on global biogeochemistry. Forest soils in particular have been identified as an efficient sink for atmospheric $\mathrm{CH}_{4}$ and are highly sensitive to land use change (Dunfield, 2007). Here, we have characterized methanotrophs in ADE and their adjacent soils (Haplic Acrisol and Oxisol) under two different land uses (i.e., secondary forest and manioc cultivation). These approaches showed two major outcomes with respect to ADE soils: (1) high $\mathrm{CH}_{4}$ oxidation rates were observed in three of four ADE soils examined, and (2) high relative and absolute abundances of methanotrophs belonging to the USC $\alpha$ pmoA cluster associated with atmospheric $\mathrm{CH}_{4}$ oxidation in upland soils were observed in all ADE soil samples, independent of land use.

\section{$\mathrm{CH}_{4}$ OXIDATION POTENTIALS}

The $\mathrm{CH}_{4}$ oxidation rates were relatively high in forested sites. This is in agreement with other studies of tropical forests soils (Verchot et al., 2000; Veldkamp et al., 2008; Zhang et al., 2008; Dörr et al., 2010). Surprisingly, the ADE soil at the Barro Branco site under manioc cultivation showed a $\mathrm{CH}_{4}$ oxidation rate similar to that of the forested sites. Many studies have shown that conversion of forest to agriculture diminishes $\mathrm{CH}_{4}$ uptake. For example, after 2 years of agriculture a Norwegian soil showed a fivefold decrease in $\mathrm{CH}_{4}$ oxidation rate (Jensen and Olsen, 1998). At the time of sampling, the ADE soil at Barro Branco had been used for manioc cultivation for $\sim 5$ years, suggesting that it too should have shown a decreased $\mathrm{CH}_{4}$ oxidation potential. The ADE soil at the manioc planation at the Caldeirão area, which has a longer history

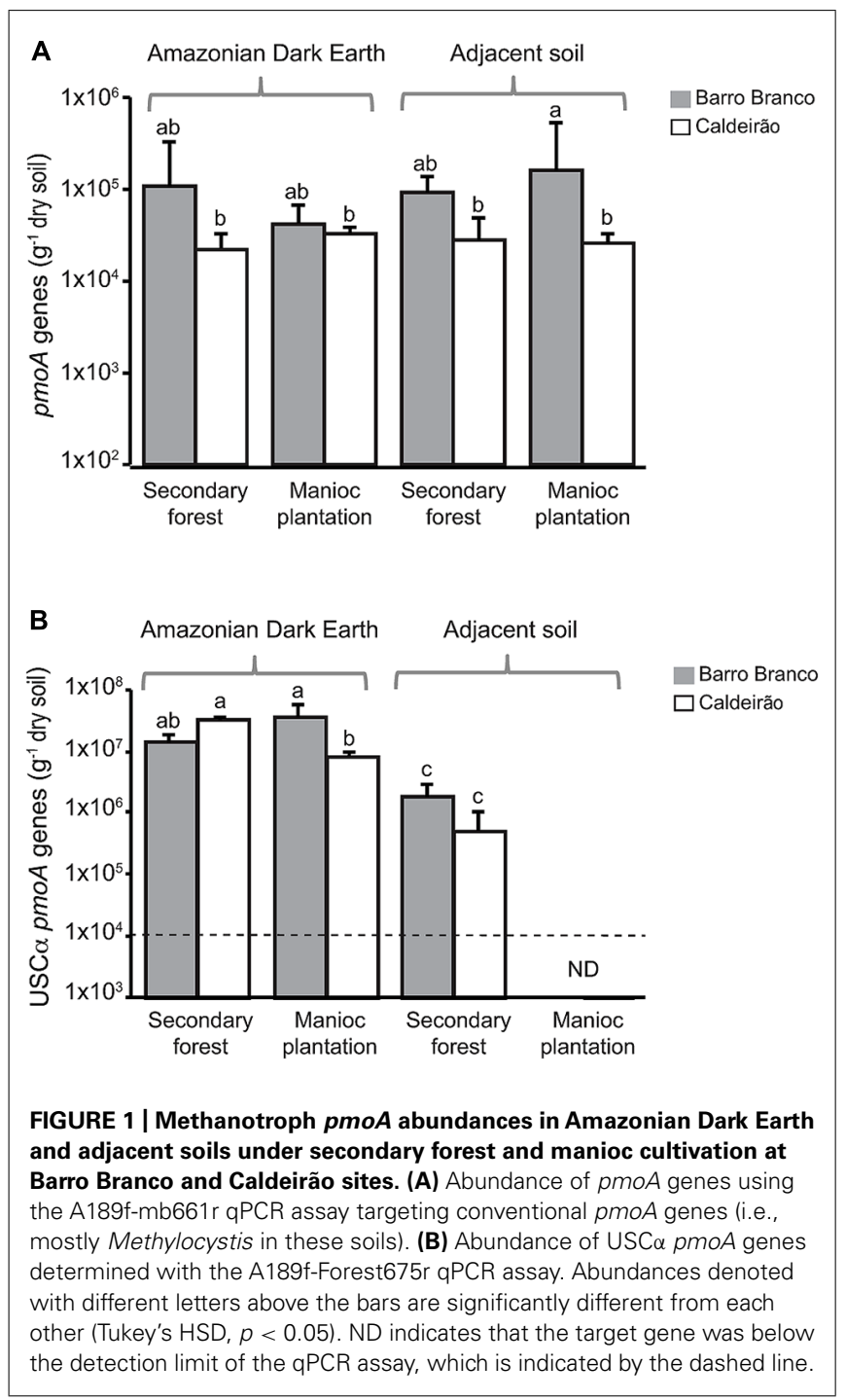

of cultivation, showed a decreased $\mathrm{CH}_{4}$ oxidation potential. The cultivated ADE site at Barro Branco had been burned to clear the land, which may have also influenced in $\mathrm{CH}_{4}$ oxidation capacity as in some cases fire has been shown stimulate atmospheric $\mathrm{CH}_{4}$ oxidation (Jaatinen et al., 2004).

\section{ABUNDANCE AND COMMUNITY COMPOSITION OF METHANOTROPHS}

Differences in the methanotroph communities were found between ADE and adjacent soils under secondary forest and manioc cultivation, indicating that the methanotrophic community is altered depending on soil type and land use. USC $\alpha$ were the predominant methanotrophs in all ADE soils and the forested adjacent soils. This group is as yet uncultivated, but is believed to be responsible for atmospheric $\mathrm{CH}_{4}$ consumption in many forest soils (Dunfield, 2007; Kolb, 2009; Nazaries et al., 2013). The abundance of USC $\alpha$ pmoA genes was $\sim 1 \times 10^{7}$ per gram dry weight in the ADE soils, which was one-order of magnitude higher than in the forested sites of the adjacent soils. In comparison, the same assay used to quantify USC $\alpha$ in a German forest soil detected $\sim 1 \times 10^{6}$ gene copies per gram dry weight of soil (Kolb 


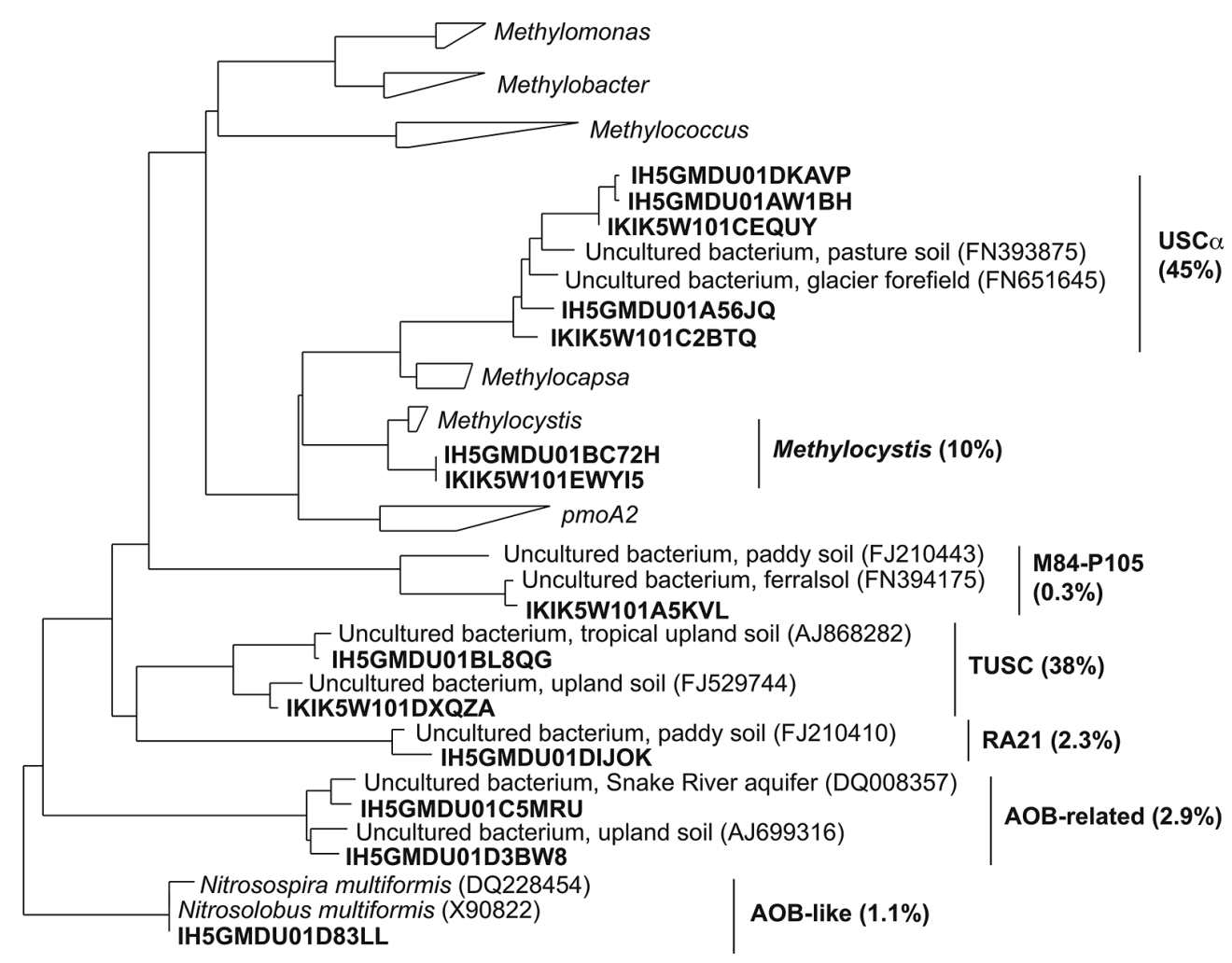

FIGURE 2 | Phylogenetic tree of representative pmoA pyrosequences (bold type) obtained in this study. The percentages of sequences corresponding to each clade are shown in parentheses.

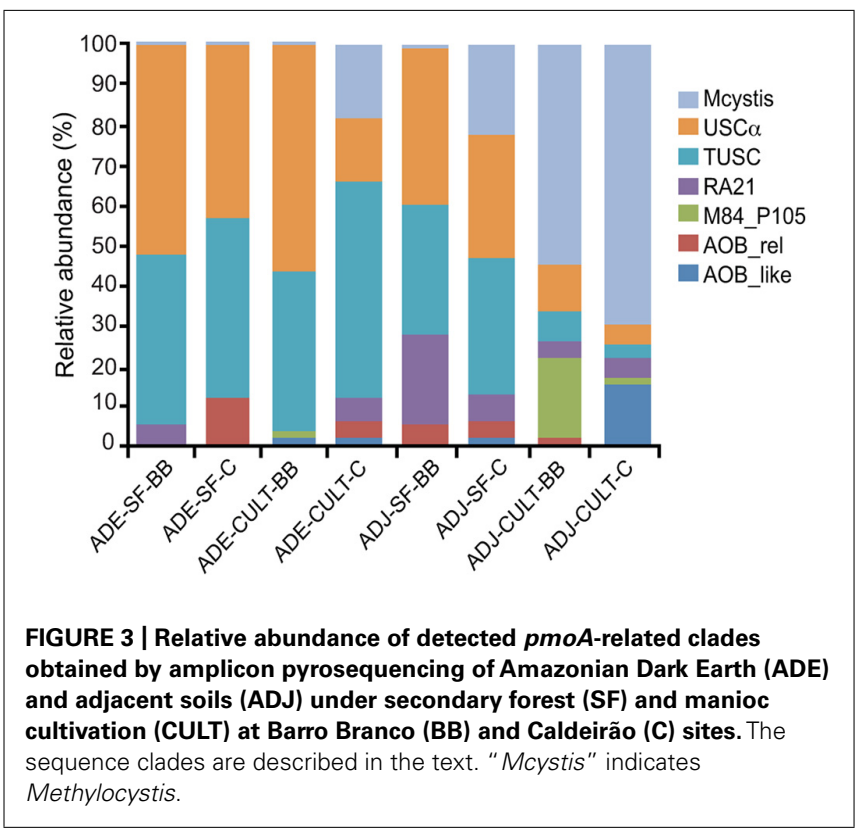

et al., 2005), suggesting that their abundance in ADE was relatively high.

It was surprising that USC $\alpha$ abundances were equally high in the cultivated and forested ADE soils (Figure 1B). This pattern was different for the adjacent soils where they were below the qPCR detection limit in the cultivated soils, indicating abundances at least two-orders of magnitude lower than the forested sites. In comparison, the manioc plantation in ADE soil at Caldeirão has a long history of agriculture use, yet the USC $\alpha$ abundance was only threefold lower than in the corresponding forested soil. To the best of our knowledge, this is the first study to detect a high absolute and relative abundance of USC $\alpha$ in agricultural soils. Priemé et al. (1997) showed that $\mathrm{CH}_{4}$ oxidation rates took more than 100 years to reach pre-cultivation levels and that the highest rates were in the oldest (200 years) woodlands. The apparent resilience of USC $\alpha$ populations in ADE soil compared with other upland soils, possibly from a protective property of ADE, suggests that recovery of $\mathrm{CH}_{4}$ oxidation capacity after agricultural abandonment might be faster in ADE than other types of upland soil.

Also of note in this study was that the $\mathrm{CH}_{4}$ uptakes rates were relatively low in cultivated $\mathrm{ADE}$ soil at Caldeirão, but USC $\alpha$ abundance in this soil was relatively high. One possible explanation for this lack of correlation is that USC $\alpha$ methanotrophs can incorporate acetate and possibly other organic carbon substrates (Pratscher et al., 2011), suggesting that $\mathrm{CH}_{4}$ oxidation is a facultative trait in these organisms and $\mathrm{CH}_{4}$ is oxidized only under certain conditions. Evidence that USC $\alpha$ are not obligate methanotrophs include reported failures to sufficiently label their nucleic acids with ${ }^{13} \mathrm{CH}_{4}$ for stable isotope probing (Bengtson 

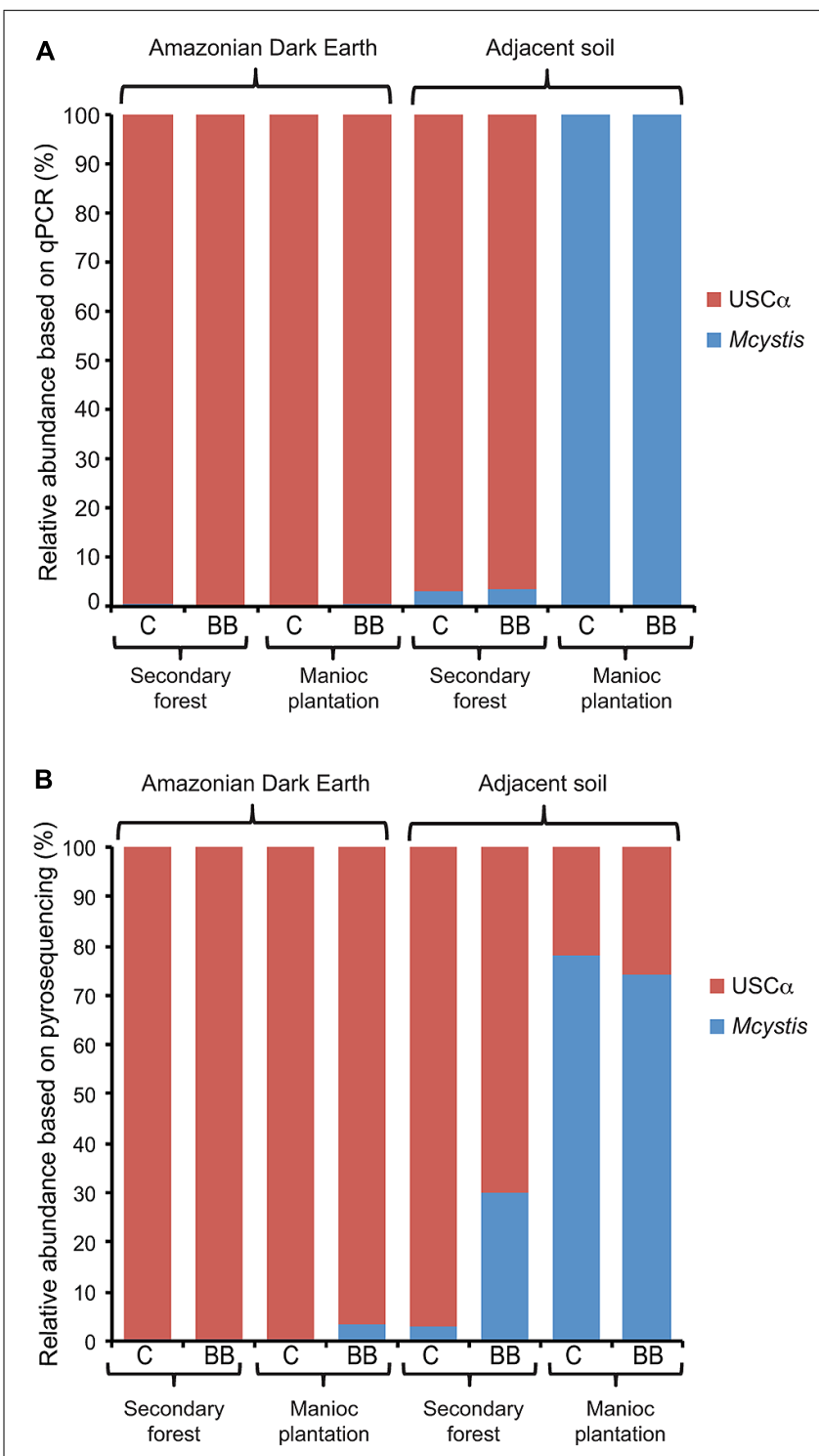

FIGURE 4 | Relative abundance of Methylocystis (Mcystis) and USC $\alpha$ pmoA genes in Amazonian Dark Earth and their adjacent soils under secondary forest and manioc cultivation at Barro Branco (BB) and Caldeirão (C) sites. Abundances calculated based on (A) qPCR or (B) pyrosequencing data.

et al., 2009; Pratscher et al., 2011), and an ability of many of their closest cultivated relatives to grow using multicarbon compounds (Tamas et al., 2014). Another possibility is that the USC $\alpha$ methanotrophs in this ADE soil at Caldeirão have been able to remain dormant, or possibly that DNA from dead cells is relatively stable in ADE soil.

The diversity of methanotrophs observed in this study was similar to the observations of Dörr etal. (2010), who observed in Brazilian ferralsols a prevalence of USC $\alpha$ in natural and afforested sites and higher relative abundances of Methylocystis and Methylococcus spp. in agricultural soil under conventional farming. Among the cultivated methanotrophs, we only detected Methylocystis pmoA and no conventional pmoA genes from Methylococcaceae methanotrophs; however, the unconventional M84-P105 pxmA sequences, which have been shown to belong to members of the Methylococceae (Tavormina etal., 2011), were detected in cultivated adjacent soils suggesting a low abundance of these methanotrophs in some soils (Figure 3). Although the relative abundance of Methylocystis was high in the adjacent soils from manioc plantation sites (Figure 3), no difference in their absolute abundance between ADE and adjacent soil, or between forested and cultivated sites was observed at this sampling time (Figure 1). Methylocystis have been shown to be important consumers of $\mathrm{CH}_{4}$ in hydromorphic soils under dry conditions when $\mathrm{CH}_{4}$ concentrations are relatively low (Knief et al., 2005). These Methylocystis possess an unconventional pMMO gene, termed pMMO2 (Ricke et al., 2004), which is expressed under low $\mathrm{CH}_{4}$ (Baani and Liesack, 2008). We only detected two pmoA2 gene sequences in our pyrosequencing dataset (data not shown), suggesting that conditions in these Amazonian soils at the time of this analysis were not favorable for $\mathrm{pMMO} 2$-possessing oligotrophic Methylocystis species.

Other pmoA-related gene sequences were detected, such as TUSC, AOB-rel and AOB-like groups. The AOB-like sequences correspond to the amoA genes of Nitrosospira and Nitrosomonas (Figure 2). In $\mathrm{ADE}$ soils, these amo $A$ sequences were only detected in plantation soil, which is likely a consequence of enrichment by ammonium fertilizer applied to the soil for manioc cultivation. The TUSC and AOB-rel groups have not been linked to cultivated organisms and the function of the enzyme encoded by these genes is not known (Lüke and Frenzel, 2011). TUSC or "tropical upland soil cluster" is also termed "Cluster 2" elsewhere (Knief et al., 2005). As the name implies, they were found to be abundant in some tropical upland soils (Knief et al., 2005), but have also been detected in temperate forest soil (Knief et al., 2003). It is noteworthy that the relative abundance of TUSC tended to mirror USC $\alpha$ in these Amazonian soils. One possibility to explain this correlation is that TUSC sequences are a divergent $p m o A$ gene found in USC $\alpha$ methanotrophs, such as the case with M84-P105 pxmA in Methylomonas and pmoA2 in Methylocystis; however, other studies have not observed a correlation between USC $\alpha$ and TUSC relative abundances (Kolb, 2009; Dörr et al., 2010).

\section{CONCLUSION}

This study has shown that ADE soils are a potential sink for atmospheric $\mathrm{CH}_{4}$. The relatively high rate of "high-affinity" $\mathrm{CH}_{4}$ uptake by the ADE soil with a 5-year history of agriculture contradicts many studies showing the process to be sensitive to land use change. All the ADE soils examined had a high abundance of USC $\alpha$ methanotrophs $\left(\sim 10^{7}\right.$ pmoA genes $g^{-1}$ soil), which was particularly surprising for the $\mathrm{ADE}$ soil at the Caldeirão site that had a long history of manioc cultivation. In comparison, the abundance of USC $\alpha$ methanotrophs was up to 1000-fold lower in adjacent than ADE soil, and both the adjacent soils used for agriculture displayed relatively low $\mathrm{CH}_{4}$ uptake rates. This raises the question if USC $\alpha$ methanotrophs are indeed more resistant to disturbance in $\mathrm{ADE}$ than in other upland soils and whether this apparent resilience of $\mathrm{ADE}$ extends to the protection of other groups of vulnerable microorganisms and their associated functions. 


\section{ACKNOWLEDGMENTS}

We thank R. B. Correa and I. G. Braga for assistance with the fieldwork and Prof. R. Conrad for helpful discussions. We also would like to thank W. G. Teixeira and G. C. Martins for soil descriptions and members from the community of Barro Branco. This research was supported by the Max Planck Society, CNPq (Conselho Nacional de Desenvolvimento Científico e Tecnológico), FAPEAM (Fundação de Amparo à Pesquisa do Estado do Amazonas), and EMBRAPA Western Amazon. Amanda B. Lima received a postdoctoral scholarship from $\mathrm{CNPq}$ within the program Science Without Borders (CsF).

\section{SUPPLEMENTARY MATERIAL}

The Supplementary Material for this article can be found online at: http://www.frontiersin.org/journal/10.3389/fmicb.2014.00550/ abstract

\section{REFERENCES}

Anderson, C. R., Condron, L. M., Clough, T. J., Fiers, M., Stewart, A., Hill, R. A., et al. (2011). Biochar induced soil microbial community change: implications for biogeochemical cycling of carbon, nitrogen and phosphorus. Pedobiologia 54, 309-220. doi: 10.1016/j.pedobi.2011.07.005

Angel, R., and Conrad, R. (2009). In situ measurement of methane fluxes and analysis of transcribed particulate methane monooxygenase in desert soils. Environ. Microbiol. 11, 2598-2610. doi: 10.1111/j.1462-2920.2009.01984.x

Baani, M., and Liesack, W. (2008). Two isozymes of particulate methane monooxygenase with different methane oxidation kinetics are found in Methylocystis sp. Strain SC2. Proc. Natl. Acad. Sci. U.S.A. 105, 10203-10208. doi: 10.1073/pnas.0702643105

Bengtson, P., Basiliko, N., Dumont, M. G., Hills, M., Murrell, J. C., Roy, R., et al. (2009). Links between methanotroph community composition and $\mathrm{CH}_{4}$ oxidation in a pine forest soil. FEMS Microbiol. Ecol. 70, 356-366. doi: 10.1111/j.1574-6941.2009.00751.x

Berry, D., Mahfoudh, K. B., Wagner, M., and Loy, A. (2011). Barcoded primers used in multiplex amplicon pyrosequencing bias amplification. Appl. Environ. Microbiol. 77, 7846-7849. doi: 10.1128/AEM.05220-11

Bodelier, P. L. E., Gillisen, M.-J. B., Hordijk, K., Damsté, J. S. S., Rijpstra, W. I. C., Geenevasen, J. A. J., et al. (2009). A reanalysis of phospholipid fatty acids as ecological biomarkers for methanotrophic bacteria. ISME J. 3, 606-617. doi: 10.1038/ismej.2009.6

Bourne, D. G., McDonald, I. R., and Murrell, J. C. (2001). Comparison of pmoA PCR primer sets as tools for investigating methanotroph diversity in three Danish soils. Appl. Environ. Microbiol. 67, 3802-3809. doi: 10.1128/AEM.67.9.3802-3809.2001

Brossi, M. J. L., Mendes, L. W., Germano, M. G., Lima, A. B., and Tsai, S. M. (2014). Assessment of bacterial bph gene in Amazonian Dark Earth and their adjacent soils. PLoS ONE 9:e99597. doi: 10.1371/journal.pone.0099597

Bull, I. D., Parekh, N. R., Hall, G. H., Ineson, P., and Evershed, R. P. (2000). Detection and classification of atmospheric methane oxidizing bacteria in soil. Nature 405, 175-178. doi: 10.1038/35012061

Cochrane, T. T., and Sanchez, P. A. (1982). Land Resources, Soils and their Management in the Amazon Region: A State of Knowledge Report. Cali: Centro Internacional de Agricultura Tropical-CIAT.

Costa, M. L., and Kern, D. C. (1999). Geochemical signatures of tropical soils with archaeological black earth in the Amazon. J. Geochem. Explor. 66, 369-385. doi: 10.1016/S0375-6742(99)00038-2

Costello, A. M., and Lidstrom, M. E. (1999). Molecular characterization of functional and phylogenetic genes from natural populations of methanotrophs in lake sediments. Appl. Environ. Microbiol. 65, 5066-5074.

Dalal, R. C., and Allen, D. E. (2008). Greenhouse gas fluxes from natural ecosystems. Aust. J. Bot. 56, 369-407. doi: 10.1071/BT07128

Denevan, W. M. (1998). Comments on prehistoric agriculture in Amazônia. Cult. Agric. 20, 54-59. doi: 10.1525/cag.1998.20.2-3.54

Denman, K. L., Brasseur, G., Chidthaisong, A., Ciais, P., Cox, P. M., Dickinson, R. E., et al. (2007). "Couplings between changes in the climate system and biogeochemistry," in Climate Change 2007: The Physical Science Basis, eds S. Solomon, D.
Qin, M. Manning, Z. Chen, M. Marquis, K. Averyt, et al. (Cambridge: Cambridge University Press), 499-587.

Dörr, N., Glaser, B., and Kolb, S. (2010). Methanotrophic communities in Brazilian ferralsols from naturally forested, afforested, and agricultural sites. Appl. Environ. Microbiol. 76, 1307-1310. doi: 10.1128/AEM.02282-09

Dumont, M. G., Lüke, C., Deng, Y., and Frenzel, P. (2014). Classification of pmoA amplicon pyrosequencing using BLAST and the lowest common ancestor method in MEGAN. Front. Microbiol. 5:34. doi: 10.3389/fmicb.2014.00034

Dunfield, P. F. (2007). “The soil methane sink," in Greenhouse Gas Sinks, eds D. Reay, C. N. Hewitt, K. Smith, and J. Grace (Wallingford: CABI Publishing).

Edgar, R. C., Haas, B. J., Clemente, J. C., Quince, C., and Knight, R. (2011). UCHIME improves sensitivity and speed of chimera detection. Bioinformatics 27, 21942200. doi: 10.1093/bioinformatics/btr381

Embrapa. (1997). Manual de Métodos de Análise de Solo. Rio de Janeiro: EmbrapaCNPS.

FAO. (1998). World Reference Base for Soil Resources. World Soil Resources Report 84 FAO. Rome: UN Food and Agriculture Organization, 88.

Glaser, B. (1999). Eigenschaften und Stabilität des Humuskörpers der Indianerschwarzerden Amazoniens. Bayreuther Bodenkundliche Ber. 68, 1-196.

Holmes, A. J., Costello, A., Lidstrom, M. E., and Murrell, J. C. (1995). Evidence that particulate methane monooxygenase and ammonium monooxygenase may be evolutionarily related. FEMS Microbiol. Lett. 132, 203-208. doi: 10.1111/j.15746968.1995.tb07834.x

Horz, H. P., Raghubanshi, A. S., Heyer, J., Kammann, C., Conrad, R., and Dunfield, P. F. (2002). Activity and community structure of methane-oxidising bacteria in a wet meadow soil. FEMS Microbiol. Ecol. 41, 247-257. doi: 10.1111/j.15746941.2002.tb00986.x

Horz, H. P., Rich, V., Avrahami, S., and Bohannan, B. J. (2005). Methaneoxidizing bacteria in a California upland grassland soil: diversity and response to simulated global change. Appl. Environ. Microbiol. 71, 2642-2652. doi: 10.1128/AEM.71.5.2642-2652.2005

Huson, D. H., Mitra, S., Ruscheweyh, H. J., Weber, N., and Schuster, S. C. (2011). Integrative analysis of environmental sequences using MEGAN4. Genome Res. 21, 1552-1560. doi: 10.1101/gr.120618.111

Hütsch, B. W., Webster, C. P., and Powlson, D. S. (1994). Methane oxidation in soil as affected by land use, soil pH and $\mathrm{N}$ fertilization. Soil Biol. Biochem. 26, 1613-1622. doi: 10.1016/0038-0717(94)90313-1

Jaatinen, K., Knief, C., Dunfield, P. F., Yrjälä, K., and Fritze, H. (2004). Methanotrophic bacteria in boreal forest soil: long-term effects of prescribed burning and wood ash fertilization. FEMS Microbiol. Ecol. 50, 195-202. doi: 10.1016/j.femsec.2004.06.013

Jensen, S., and Olsen, R. A. (1998). Atmospheric methane consumption in adjacent arable and forest soil systems. Soil Biol. Biochem. 30, 1187-1193. doi: 10.1016/S0038-0717(97)00149-1

Jesus, E. C., Marsch, T. L., Tiedje, J. M., and Moreira, F. M. S. (2009). Changes in land use alter the structure of bacterial communities in Western Amazon soils. ISME J. 3, 1004-1011. doi: 10.1038/ismej.2009.47

Keller, M., Mitre, M. E., and Stallard, R. F. (1990). Consumption of atmospheric methane in soils of central Panama: effects of agricultural development. Global Biogeochem. Cycles 4, 21-27. doi: 10.1029/GB004i001p00021

Khodadad, C. L. M., Zimmerman, A. R., Green, S. J., Uthandi, S., and Foster, J. S. (2011). Taxa-specific changes in soil microbial community composition induced by pyrogenic carbon amendments. Soil Biol. Biochem. 43, 385-392. doi: 10.1016/j.soilbio.2010.11.005

King, G. M. (1992). Ecological aspects of methane consumption, a key determinant of global methane dynamics. Adv. Microb. Ecol. 12, 431-468. doi: 10.1007/978-14684-7609-5_9

Knief, C., and Dunfield, P. F. (2005). Response and adaptation of methanotrophic bacteria to low methane concentrations. Environ. Microbiol. 7, 1307-1317. doi: 10.1111/j.1462-2920.2005.00814.x

Knief, C., Kolb, S., Bodelier, P. L. E., Lipski, A., and Dunfield, P. F. (2006). The active methanotrophic community in hydromorphic soils change in response to changing methane concentration. Environ. Microbiol. 8, 321-333. doi: 10.1111/j.1462-2920.2005.00898.x

Knief, C., Lipski, A., and Dunfield, P. F. (2003). Diversity and activity of methanotrophic bacteria in different upland soils. Appl. Environ. Microbiol. 69, 6703-6714. doi: 10.1128/AEM.69.11.6703-6714.2003

Knief, C., Vanitchung, S., Harvey, N. W., Conrad, R., Dunfield, P. F., and Chidthaisong, A. (2005). Diversity of methanotrophic bacteria in tropical upland 
soils under different land use. Appl. Environ. Microbiol. 71, 3826-3831. doi: 10.1128/AEM.71.7.3826-3831.2005

Knoblauch, C., Marifaat, A. A., and Haefele, M. S. (2008). Biochar in Rice-Based System: Impact on Carbon Mineralization and Trace Gas Emissions. Available at: http://www.biochar-international.org/2008/conference/posters (accessed June 27, 2014).

Kolb, S. (2009). The quest for atmospheric methane oxidizers in forest soils. Environ. Microbiol. Rep. 1, 336-346. doi: 10.1111/j.1758-2229.2009.00047.x

Kolb, S., Knief, C., Dunfield, P. F., and Conrad, R. (2005). Abundance and activity of uncultured methanotrophic bacteria involved in the consumption of atmospheric methane in two forest soils. Environ. Microbiol. 7, 1150-1161. doi: 10.1111/j.14622920.2005.00791.x

Kolb, S., Knief, C., Stubner, S., and Conrad, R. (2003). Quantitative detection of methanotrophs in soil by novel pmoA targeted real-time PCR assays. Appl Environ. Microbiol. 69, 2423-2429. doi: 10.1128/AEM.69.5.2423-2429.2003

Lehmann, J. (2007). Bio-energy in the black. Front. Ecol. Environ. 5:381-387. doi: 10.1890/1540-9295(2007)5[381:BITB]2.0.CO;2

Levine, U. Y., Teal, T. K., Robertson, G. P., and Schmidt, T. M. (2011). Agriculture's impact on microbial diversity and associated fluxes of carbon dioxide and methane. ISME J. 5, 1683-1691. doi: 10.1038/ismej.2011.40

Ludwig, W., Strunk, O., Westram, R., Richter, L., Meier, H., Yadhukumar, et al. (2004). ARB: a software environment for sequence data. Nucleic Acids Res. 32, 1363-1371. doi: 10.1093/nar/gkh293

Lüke, C., and Frenzel, P. (2011). Potential of pmoA amplicon pyrosequencing for methanotroph diversity studies. Appl. Environ. Microbiol. 77, 6305-6309. doi 10.1128/AEM.05355-11

McDonald, I. R., Bodrossy, L., Chen, Y., and Murrell, C. (2008). Molecular ecology techniques for the study of aerobic methanotrophs. Appl. Environ. Microbiol. 74 1305-1315. doi: 10.1128/AEM.02233-07

Mosier, A., Schimel, D., Valentine, D., Bronson, K., and Parton, W. (1991). Methane and nitrous oxide fluxes in native, fertilized and cultivated grasslands. Nature 350, 330-332. doi: 10.1038/350330a0

Navarrete, A. A., Cannavan, F. S., Taketani, R. G., and Tsai, S. M. (2010). A molecular survey of the diversity of microbial communities in different Amazonian agricultural model systems. Diversity 2, 787-809. doi: 10.3390/d20 50787

Nazaries, L., Pan, Y., Bodrossy, L., Baggs, E. M., Millard, P., Murrell, J. C., et al. (2013). Evidence of microbial regulation of biogeochemical cycles from a study on methane flux and land use change. Appl. Environ. Microbiol. 79, 4031-4040. doi: 10.1128/AEM.00095-13

Neher, D. A. (1999). Soil community composition and ecosystem processes comparing agricultural ecosystems with natural ecosystems. Agrofor. Syst. 45, 159-185. doi: 10.1023/A:1006299100678

Pratscher, J., Dumont, M. G., and Conrad, R. (2011). Assimilation of acetate by the putative atmospheric methane oxidizers belonging to the USC $\alpha$ clade. Environ. Microbiol. 13, 2692-2701. doi: 10.1111/j.1462-2920.2011.02537.x

Priemé, A., and Christensen, S. (1999). Methane uptake by a selection of soils in Ghana with different land use. J. Geophys. Res. 104, 23617-23622. doi: 10.1029/1999JD900427

Priemé, A., Christensen, S., Dobbie, K. E., and Smith, K. A. (1997). Slow increase in rate of methane oxidation in soils with time following land use change from arable agriculture to woodland. Soil Biol. Biochem. 29, 1269-1273. doi: 10.1016/S00380717(97)00017-5

Ricke, P., Erkel, C., Kube, M., Reinhardt, R., and Liesack, W. (2004). Comparative analysis of the conventional and novel pmo (particulate methane monooxygenase) operons from Methylocystis strain SC2. Appl. Environ. Microbiol. 70, 3055-3063. doi: 10.1128/AEM.70.5.3055-3063.2004

Ricke, P., Kube, M., Nakagawa, S., Erkel, C., Reinhardt, R., and Liesack, W. (2005). First genome data from uncultured upland soil cluster alpha methanotrophs provide further evidence for a close phylogenetic relationship to
Methylocapsa acidiphila B2 and for high-affinity methanotrophy involving particulate methane monooxygenase. Appl. Environ. Microbiol. 71, 7472-7482. doi: 10.1128/AEM.71.11.7472-7482.2005

Schloss, P. D., Westcott, S. L., Ryabin, T., Hall, J. R., Hartmann, M., Hollister, E. B., et al. (2009). Introducing mothur: open-source, platform-independent, community-supported software for describing and comparing microbial communities. Appl. Environ. Microbiol. 75, 7537-7541. doi: 10.1128/AEM.01541-09

Semrau, J. D., DiSpirito, A. A., and Yoon, S. (2010). Methanotrophs and copper. FEMS Microbiol. Rev. 34, 496-531. doi: 10.1111/j.1574-6976.2010.00212.x

Shrestha, P. M., Kammann, C., Lenhart, K., Dam, B., and Liesack, W. (2012). Linking activity, composition and seasonal dynamics of atmospheric methane oxidizers in a meadow soil. ISME J. 6, 1115-1126. doi: 10.1038/ismej.2011.179

Smith, N. J. H. (1980). Anthrosols and human carrying capacity in Amazonia. Ann Assoc. Am. Geogr. 70, 553-566. doi: 10.1111/j.1467-8306.1980.tb01332.x

Sombroek, W., De Lourdes Ruivo, M., Fearnside, P., Glaser, B., and Lehmann, J. (2003). "Amazonian dark earths as carbon stores and sinks," in Amazonian Dark Earths: Origin, Properties, Management, eds J. Lehmann, D. C. Kern, B. Glaser, and W. I. Woods (Dordrecht: Kluwer Academic Publishers), 141-158.

Taketani, R. G., Lima, A. B., Jesus, E. C., Teixeira, W. G., Tiedje, E. C., and Tsai, S. M. (2013). Bacterial community composition of anthropogenic biochar and Amazonian anthrosols assessed by $16 \mathrm{~S}$ rRNA gene 454 pyrosequencing. Antonie van Leeuwenhoek 104, 233-242. doi: 10.1007/s10482-013-9942-0

Tamas, I., Smirnova, A. V., He, Z., and Dunfield, P. F. (2014). The (d)evolution of methanotrophy in the Beijerinckiaceae-a comparative genomics analysis. ISME J. 8, 369-382. doi: 10.1038/ismej.2013.145

Tavormina, P. L., Orphan, V. J., Kalyuzhnaya, M. G., Jetten, M. S. M., and Klotz, M. G. (2011). A novel family of functional operons encoding methane/ammonia monooxygenase-related proteins in gammaproteobacterial methanotrophs. Environ. Microbiol. Rep. 3, 91-100. doi: 10.1111/j.17582229.2010.00192.x

Veldkamp, E., Purbopuspito, J., Corre, M. D., Brumme, R., and Murdiyarso, D. (2008). Land use change effects on trace gas fluxes in the forest margins of Central Sulawesi, Indonesia. J. Geophys. Res. 113, G02003. doi: 10.1029/2007JG0 00522

Verchot, L. V., Davidson, E. A., Cattânio, J. H., and Ackerman, I. L. (2000). Landuse change and biogeochemical controls of methane fluxes in soils of Eastern Amazonia. Ecosystems 3, 41-56. doi: 10.1007/s100210000009

Woods, W. I., and McCann, J. M. (1999). The anthropogenic origin and persistence of Amazonian Dark Earths. Yearb. Conf. Lat. Am. Geogr. 25, 7-14.

Zhang, W., Mo, J., Zhou, G., Gundersen, P., Fang, Y., Lu, X., et al. (2008). Methane uptake responses to nitrogen deposition in three tropical forests in southern China. J. Geophys. Res. Atmos. 113, D11116. doi: 10.1029/2007JD009195

Conflict of Interest Statement: The authors declare that the research was conducted in the absence of any commercial or financial relationships that could be construed as a potential conflict of interest.

Received: 04 July 2014; accepted: 02 October 2014; published online: 22 October 2014. Citation: Lima AB, Muniz AW and Dumont MG (2014) Activity and abundance of methane-oxidizing bacteria in secondary forest and manioc plantations of Amazonian Dark Earth and their adjacent soils. Front. Microbiol. 5:550. doi: 10.3389/fmicb.2014.00550

This article was submitted to Terrestrial Microbiology, a section of the journal Frontiers in Microbiology.

Copyright (c) 2014 Lima, Muniz and Dumont. This is an open-access article distributed under the terms of the Creative Commons Attribution License (CC BY). The use, distribution or reproduction in other forums is permitted, provided the original author(s) or licensor are credited and that the original publication in this journal is cited, in accordance with accepted academic practice. No use, distribution or reproduction is permitted which does not comply with these terms. 